Original Article

\title{
A systematic review on the efficacies and therapeutic interventions of homoeopathic medicines in combating viral disorders with implications in the currently undergoing homoeopathic treatment efforts for SARS- CoV-2 infection (COVID-19)
}

\author{
Joy Kumar Dey ${ }^{1,2,3, \$, ;}$; Anupam Mukherjee ${ }^{4, \$ ;}$ Sanjay Kumar Dey ${ }^{3,5, \$, \# ; ~ A b h i s h e k ~ P r a m a n i k 6 ; ~}$
} Shashi Giri?; Mukut Pratap ${ }^{8}$

1Documentation and Publication Section, Central Council for Research in Homoeopathy, Ministry of AYUSH, Govt. of India, New Delhi-110058, Delhi, India;

${ }^{2}$ Homoeopathic Seva Niketan, Durga Park, New Delhi-110045, Delhi, India;

3Dey Health Care and Research Foundation, Nalikul-712407, Wes Bengal, India;

${ }^{4}$ Department of Homoeopathic Pharmacy, Bharati Vidyapeeth (Deemed to be University) - Homoeopathic Medical College and Hospital (Post-Graduate Research Centre), Pune-411043, Maharashtra, India;

${ }^{5}$ Department of Biochemistry, University of Delhi South Campus, New Delhi-110021, Delhi, India;

6Department of Organon of Medicine and Homoeopathic Philosophy, Government Homoeopathic Medical College and Hospital, AYUSH Parisar, Bhopal-462003, Madhya Pradesh, India;

${ }^{7}$ NPCDCS Section, Central Council for Research in Homoeopathy, Ministry of AYUSH, Govt. of India, New Delhi110058, Delhi, India;

${ }^{8}$ Department of Biochemistry, Central University of Rajasthan, Ajmer-305817, Rajasthan, India;

\#Current address: Center for Advanced Biotechnology and Medicine, Rutgers University, Piscataway-08854, New Jersey, USA

\$Equally contributed.

* joyhomoeo83@gmail.com - https://orcid.org/0000-0001-5735-4174

\# https://orcid.org/0000-0001-7062-9574

\begin{abstract}
The prevalence of Severe Acute Respiratory Syndrome-Corona Virus-2 (SARS-CoV-2) has undergone a historic transition from December 2019 to June 2020. Under the current circumstances, SARS-CoV2 has become a key problem for the public health and economic steadiness of the global fraternity. Based on ample evidences from the global epidemiology of SARS-CoV-2 and MERS-CoV (Middle East Respiratory Syndrome-Corona virus) scientists and physicians strappingly consider these viruses share structural and functional similarities of selected biologically active enzymes namely, 3CL pro, PLpro and RdRp. Ultra-diluted homoeopathic medicine has the legacy to combat infectious as well as viral diseases since last two centuries. Thus, a systematic review on existing antiviral homoeopathic therapies was done in the current study and the need of appropriate clinical validation with proper in vitro as well as in vivo studies prior to make clinical endorsements in treating COVID-19 patients with homoeopathic medicines has been explained. A brief summary of the currently undergoing or recently completed homoeopathic treatments of COVID-19 has also been provided to attract many more similar homoeopathic treatment attempts to combat COVID-19.
\end{abstract}

Keywords: COVID-19; SARS-CoV-2; Viral Disorders; Modified Newcastle-Ottawa Scale; Homoeopathic Treatment of COVID-19.

\section{Introduction}

The world is encountering with the new challenge of COVID-19 (Coronavirus disease-2019), an infectious disease caused by a newly discovered severe acute respiratory syndrome coronavirus 
2 (SARS-CoV-2) which is a single stranded RNA virus (1). The disease was first recognized in December 2019 in Wuhan, the capital of China's Hubei province, and has since spread worldwide, resulting a pandemic $(2,3)$. Common symptoms of this infection include fever, cough, shortness of breath, fatigue, muscle pain, diarrhoea, sore throat, loss of smell, conjunctivitis, and abdominal pain (4-6). The time to onset of symptoms from exposure is mainly around five days, but may vary from two to fourteen days (7). People infected with COVID-19 will experience a mild to moderate respiratory complaint and recover without necessitating special treatment. Older people and those with underlying medical issues like cardiovascular disease (CVD), diabetes (DM ${ }_{\mathrm{II}}$ ), chronic respiratory ailment, and cancer (CA) are more likely to develop serious disorder $(5,8)$. WHO has published several testing protocols to combat the COVID-19 (9). Among them, real-time reverse transcription polymerase chain reaction (rRT-PCR) is denoted as a standard method of testing (10), which is done on respiratory samples obtained by a nasopharyngeal swab, nasal swab or sputum sample (11).

The best way to prevent and slow down the transmission is being well informed about the SARS-CoV2 virus, the disease it causes and how it spreads. Protect yourself and others from infection by staying at home, avoiding crowded places, washing hands with soap and water often and for at least 20 seconds (better using an alcohol based rub frequently), practising good respiratory hygiene and avoiding touching your face, eyes, nose or mouth with unwashed hands (12-14).

The SARS-CoV-2 virus spread primarily through droplets of saliva or discharge from the nose when an infected person coughs or sneezes, so it is important to practice respiratory etiquette. When coughing or sneezing covering the mouth and nose with a tissue and using the flexed elbow if no tissue is available as recommended by the CDC. After every cough or sneeze, a proper hand sanitizing is necessary (12). Along with that, social distancing guidelines are recommended to reduce contact of infected persons with large herd, by staying at least six feet $(1.8 \mathrm{~m})$ apart $(15,16)$. There is no specific modern medicine known to be effective to prevent COVID-19 yet although many predictions are made, clinical trials of many medicines including remdesivir are partially successful worldwide for a solution $(17,18)$. Thus, the development of new therapies, including homoeopathy, that can prevent and/or treat this disease holds promise urging detailed evaluation of its anti-viral efficacies, if any. Globally, as of 2:00 am CEST, $14^{\text {th }}$ June 2020, there have been more than $7.700,000$ confirmed cases of COVID-19, including 430,000 deaths have been reported (19). Therefore, in view of the present appalling scenario, governments and policy makers around the globe should think of integration and promotion of various alternative therapies, especially homoeopathy, for handling the current crisis situation.

Amidst of these, homoeopathic system of medicine offers the sufficient evidences to be used as preventive and as treatment modality in various dreadful epidemics such as typhoid, cholera, yellow fever, scarlet fever, meningitis etc. epidemic cases, there is anecdotal evidence that homoeopathy was successful during the Spanish flu epidemic of 1918 to 1919, in which at least 20 million people died worldwide. Current study has thus curated the existing studies of homoeopathy used for the treatment of infectious viral diseases across the world and formulated the best practices of the same for its plausible future systematic use in case of SARS-CoV-2. However, the later needs proper validation. A review of the currently undergoing or recently completed homoeopathic treatments of COVID-19 has also been conducted in this study to attract many more similar homoeopathic treatment attempts to combat COVID-19. 


\section{Materials and methods}

\section{Inclusion strategy}

An intensive search was conducted for previous research works of antiviral homoeopathic therapies [ $n=8$ ] of different experimental models, the pre-clinical studies [ $n=5]$ [1-5], from the clinical observational retrospective studies [n=2] [6 and 7] and from the clinical trial [n=1] [8] of the last 20 years on viral infections treated with homoeopathic medicines.

\section{Data sources}

Data were collected from the Library of Central Council for Research in Homoeopathy, India; Cochrane Library; Google Scholar, PubMed and AYUSH portal, India.

\section{Data extraction}

Data were extracted from the available research works of antiviral homoeopathic therapies $[n=8]$ of different experimental models, i.e. the pre-clinical studies [n=5] [1-5], from the clinical observational retrospective studies [ $n=2$ ] [ 6 and 7] and from the clinical trial [n=1] [8] based on a Manuscript Information Score (MIS) as explained below.

\section{Assessment}

After the extraction of research data, they were evaluated through a designed assessment tool which met up all the criteria. Assessment done by the MIS (Table 1), aimed to deliver a clear understanding of each of these assessed studies.

This scale was originally developed by the Sabine D. Klein et. al. to assess the quality of studies to be included in systematic reviews or meta-analysis (20).

\section{Systematic review of homoeopathic treatment against viral infections}

\section{Pre-clinical studies:}

1. An in vitro study was done with homoeopathic combination named as Euphorbium compositum S (Glatthaar-Saalmüller B. et al., 2001) which is commonly prescribed for aggravation of the mucosae of the nose and sinuses is accessible as drops, nasal spray, and injectable form, to evaluate its efficacy against influenza A, respiratory syncytial infection (RSV), and herpes simplex virus type 1 (HSV-1). Results showed that it has antiviral impacts against both RSV and HSV-1, but insignificant effect against influenza A virus. However, analyses of the plant-derived components of Euphorbium compositum SN, e.g. Euphorbium resinifera, Pulsatilla pratensis and Luffa operculata for their antiviral activities have revealed a clear activity of Euphorbium resinifera and Pulsatilla pratensis against RSV. In contrast, no effect was detected using the same protocol with Luffa operculata. So, this study suggests homoeopathic medicine has a distinct role to combat viral infections like, RSV and HSV-1 (21).

2. The effects of the homoeopathic combination Engystol (Biologische Heilmittel heel GmbH, Baden-Baden, Germany) was evaluated by plaque-reduction assays and virus titration assays, as well as by quantification of newly synthesized viral proteins in virus-specific enzyme-linked immune-sorbent assays (ELISAs) on DNA infection Adeno 5 and human rhino viruses (HRV) in vitro (Menachem Oberbaum et al., 2005). In ELISAs of infection contaminated cells shows 73\% decrease of Adeno 5 specific proteins and a 80\% decrease in HSV-1 explicit proteins treated with Engystol after disease. In titration assays, the effects appeared to be dose-dependent. Pretreatment of adenovirus with Engystol did not inhibit the infectivity of the viral suspension and 
no Engystol-induced stimulation of interferon-alpha was observed. Plaque-reduction assays with the RNA viruses, RSV and HRV, demonstrated decreases in infectivity by $37 \%$ (RSV) and 20\% (HRV), individually. So, this study demonstrates antiviral activity of the homoeopathic remedy Engystol in vitro (22).

\begin{tabular}{|c|c|c|}
\hline Parameters & Points & Measures \\
\hline \multirow[t]{3}{*}{$\begin{array}{l}\text { Experimental } \\
\text { procedure }\end{array}$} & 2 & $\begin{array}{ll}\text { Detailed information is given as follows: } \\
\text { - } & \text { Timeline of preparations and measurements/time of measurement } \\
\text { - } & \text { Randomization, blinding } \\
\text { - } & \text { Number of replicates } \\
\text { - } & \text { Number of measurements } \\
\text { - } & \text { Treatment/handling of the samples after potentization } \\
\end{array}$ \\
\hline & 1 & Only some details are described or few information about the setup is giver \\
\hline & $\mathbf{0}$ & No information is given about the experimental setup \\
\hline \multirow{3}{*}{ Materials } & 2 & All materials used in the experiments are described with trade name, etc. \\
\hline & 1 & Some materials used in the experiments are described or mentioned \\
\hline & $\mathbf{0}$ & No information is given about the materials used \\
\hline \multirow{3}{*}{$\begin{array}{l}\text { Measuring } \\
\text { instruments }\end{array}$} & 2 & $\begin{array}{l}\text { Measuring instruments are described in detail, operation mode, trade name } \\
\text { type, etc. }\end{array}$ \\
\hline & 1 & Measuring instruments are only mentioned \\
\hline & $\mathbf{0}$ & There is no information about measuring instruments in the paper \\
\hline \multirow{3}{*}{ Potentization } & 2 & $\begin{array}{l}\text { Potentization technique, date and time of potentization, and potentization } \\
\text { medium are described in detail }\end{array}$ \\
\hline & 1 & $\begin{array}{l}\text { - Some information about potentization technique is given } \\
\text { - Ordered from company without further details (e.g. Material 30c') }\end{array}$ \\
\hline & $\mathbf{0}$ & $\begin{array}{l}\text { No information about potentization, only the potentised test substance is } \\
\text { mentioned }\end{array}$ \\
\hline \multirow{3}{*}{ Controls } & 2 & $\begin{array}{l}\text { Detailed information (e.g. sterile distilled water from the same } \\
\text { batch of distilled water) }\end{array}$ \\
\hline & 1 & $\begin{array}{l}\text { Some information about the type of control is given (e.g. water control) ol } \\
\text { other potency levels serve as control }\end{array}$ \\
\hline & $\mathbf{0}$ & Controls are not mentioned or done \\
\hline
\end{tabular}

Five assessment areas were given a score between 0 and 2, leading to a maximum of 10 points. Only studies with MIS $\geq 5$ were included in this systematic review. MIS: Manuscript Information Score.

3. The antiviral activity of Gripp-Heel, a homoeopathic combination, was shown in the treatment of respiratory viral infections, for various types of influenza and the common cold (Bernadette Glatthaar-Saalmüller, 2007). The antiviral activity of Gripp-Heel in vitro on human pathogenic enveloped and non-enveloped RNA and DNA viruses were investigated in this work. Prior to the antiviral studies, in vitro cytotoxicity of Gripp-Heel was determined with cells (HeLa, Hep-2, MDCK, and BGM) used for the infection experiments just as with mitogen-invigorated peripheral blood mononuclear leukocytes. The antiviral action was resolved against a wide range of encompassed and non-wrapped DNA and RNA viral infections with plaque decrease test, cytopathogenic measures, infection titrations, investigation of the viral proteins in infection explicit catalyst immunoassays, and haemagglutination tests. Control substances were acyclovir (10 $\mathrm{mg} / \mathrm{mL}$ ), and amantadine hydrochloride $(5 \mathrm{mg} / \mathrm{mL})$, contingent upon the infection type. GrippHeel showed dose-dependent in vitro activity (significant reductions of infectivity by $20 \%$ to 40\%) against Human herpesvirus 1, Human adenovirus C serotype 5, Influenza an infection, 
Human respiratory syncytial infection, Human parainfluenza infection 3, Human rhinovirus B serotype 14, and Human coxsackie infection serotype A9 (23).

4. The in vitro effects of homoeopathic medicines were investigated against viral infections (Kerstin Roeska et al., 2010). The two ultra-low-dose preparations, Engystol and Gripp-Heel, used as antiviral agents in a prophylactic treatment convention $(2,24$ and $48 \mathrm{~h}$ pre-hatching) utilizing a plaque decrease measure and whether the meds influence the arrival of type 1 IFN in infection vulnerable cell lines and human fringe blood mononuclear cells (PBMCs), have exhibited prophylactic impact against viral respiratory infection and replication. In any case, when the incubation was proceeded for as long as five days, these two homoeopathic drugs displayed an articulated antiviral effect which was reliant on the incubation time. Additionally, in co-animated HeLa cells just as in enacted PBMCs Gripp-Heel and Engystol showed an increased type 1 IFN production. So, this study suggests that Engystol and Gripp-Heel inhibited the replication of a variety of respiratory viruses by stimulating type 1 IFN release in different cell systems which suggests that their antiviral activity may be mediated possibly via modulation of the antiviral type 1 IFN host response (24).

5. The in vitro antiviral efficacies of homoeopathic medicines were studied against Influenza viruses which cause exceptionally intense infectious respiratory illnesses with significant mortality, particularly among small kids, old individuals, and people with comorbid ailments. Biotherapies are diluted solutions prepared from biological products compounded following homoeopathic procedures (Camila Monteiro Siqueira et al., 2013). The ultra-diluted influenza virus solution was set up in the homoeopathic dilution $30 \mathrm{dH}$ and it was named as Influenzinum RC. The cell modifications prompted by this arrangement were investigated by optical and electron microscopies, MTT assay and impartial red tests. Glycolytic digestion (PFK-1) was concentrated by spectrophotometric examinations. Furthermore, the creation of tumour necrosis factor- $\alpha$ (TNF- $\alpha$ ) by J774.G8 macrophage cells was evaluated by ELISA for H3N2 influenza viral disorder and its treatment. Influenzinum RC didn't cause cytotoxic impacts yet initiated morphological adjustments in Madin-Darby canine kidney (MDCK) cells. After 30 days of treatment, a noteworthy increment $(\mathrm{p}<0.05)$ in mitosis rate was distinguished compared to control. MDCK mitochondrial action was changed after treatment for 10 and 30 days, respectively. Treatment altogether decreased $(\mathrm{p}<0.05)$ PFK-1 action. TNF- $\alpha$ in biotherapy-stimulated J774.G8 macrophages demonstrated a significant $(\mathrm{p}<0.05)$ increase in infected cell death as evident from the cell supernatant investigations. Influenzinum RC also modified cell morphology and biochemical features of MDCK and J774G8 cells (25).

\section{Clinical observational retrospective studies:}

6. The efficacies of homoeopathic medicines were studied to treat Influenza virus flu, a widespread disease which is responsible for hundreds of thousands of deaths passing every year (Ana Luiza Marques de Oliveira et al., 2011). About $20 \%$ of children and $5 \%$ of adults are tainted with this infection consistently. The disease is exceptionally infectious and its transmission happens by spit particles of the contaminated individual, spread by breathing, talking and coughing. Influenza pandemics are for the most part brought about by the presence of new subtype of the infection in people, which happens because of the highly mutated modified versions of influenza strains transmitted to people. In spite of many antiviral medications, this virus develops mutations, creating resistance to those drugs in few days. Their study is a literature review on the treatment of influenza with biotherapeutics utilized in clinical medication, namely, Influenzinum and Oscilococcinum. The results indicated that the two prescriptions are generally 
utilized in clinical medication. Influenzinum $9 \mathrm{CH}$ is recommended for influenza counteraction and treatment, while Oscilococcinum is increasingly used to diminish the serious side-effects in patients who as of now have this season's flu virus. In view of these results, it is conceivable to state that Influenzinum has a significant role in the counteraction and treatment of the flu and Oscilococcinnum is thus valuable in the alleviation of the adverse pathologic effects brought about by this ailment (26).

7. A prospective, multi-centre, data collection survey in India was conducted during the 2009 pandemic of A/H1N1 influenza ('swine flu', SF) by homoeopathic management based on: symptoms of patients at presentation and at follow-up (FU) and homoeopathic medicines prescribed. Authors collected data from 23 homoeopathic physicians at the peak of the pandemic (October 2009 to February 2010) (Robert T Mathie et al., 2013). Records included were: patients were immunized against A/H1N1, influenza symptoms at consultation, the homoeopathic medicines prescribed and any antiviral medicine prescribed. 1126 patients had swine flu symptoms at the first consultation, among them mild rise of temperature, cough and rhinorrhoea were commonly observed $(n=170 ; 15.1 \%)$ and a total of 44 different medicines were used, amidst of these, Arsenicum album was prescribed most frequently ( $\mathrm{n}=265 ; 23.5 \%)$. 99 followup consultations were recorded where Arsenicum album was prescribed most frequently $(\mathrm{n}=28$; $28.0 \%)(27)$.

\section{Clinical trial:}

8. A metanalysis of randomized, placebo-controlled trials of homoeopathic medicine Oscillococcinum was conducted in the prevention and / or treatment of influenza and influenzalike illness in adults or children, showing Oscillococcinum is more effective than placebo in the prevention and / or treatment of influenza and influenza-like illness in adults or children (Robert T Mathie et al., 2015). Authors included six studies: two prophylaxis trials (327 young to middleaged adults in Russia) and four treatment trials (1196 teenagers and adults in France and Germany). There was no statistically significant difference showed between the effects of Oscillococcinum and placebo in the influenza-like illness prevention: where risk ratio (RR) 0.48 , $95 \%$ confidence interval (CI) 0.17 to 1.34 , P value $=0.16$. After $48 \mathrm{~h}$ of commencing treatment, there was an absolute risk reduction of $7.7 \%$ in the frequency of symptom relief with Oscillococcinum compared with that of placebo (risk difference (RD) 0.077 ; $95 \%$ CI 0.03 to 0.12 ); the RR was 1.86 (95\% CI 1.27 to 2.73; p=0.001). A significant but lesser effect was observed at three days (RR 1.27, 95\% CI 1.03 to 1.56 ; $p=0.03$ ), and no significant difference between the groups was noted at four days (RR $1.11,95 \%$ ci 0.98 to $1.27 ; \mathrm{p}=0.10$ ) or at five days (RR 1.06; $95 \%$ CI 0.96 to 1.16 ; $\mathrm{p}=0.25$ ). Although, there was no evidence of clinically significant harm can occur due to Oscillococcinum, there is inadequate evidence to support strong conclusions to be made about Oscillococcinum in the prevention or treatment of influenza and influenza-like illness (28).

\section{Evaluation of the quality of each study}

Authors extracted data and assessed methodological quality independently. A total of eight research studies as mentioned above were included in the current systematic-review based on a criteria of $>5$ MIS (Table 2 ). 
Table 2: Score according to MIS (Manuscript Information Score):

\begin{tabular}{|c|c|c|c|c|c|c|c|c|c|}
\hline $\begin{array}{l}\text { Sl. } \\
\text { No. }\end{array}$ & Authors Name & $\begin{array}{c}\text { Year of } \\
\text { Publication }\end{array}$ & Journal & $\begin{array}{c}\text { Experimental } \\
\text { procedure }\end{array}$ & Materials & $\begin{array}{c}\text { Measuring } \\
\text { instruments }\end{array}$ & Potentization & Controls & Score \\
\hline \multicolumn{10}{|c|}{ Pre-clinical studies } \\
\hline 1 & $\begin{array}{l}\text { Glatthaar-Saalmüller } \\
\text { B. et al.(21) }\end{array}$ & 2001 & $\begin{array}{l}\text { Complementary Medicine } \\
\text { Research }\end{array}$ & 2 & 2 & 2 & 1 & 1 & 8 \\
\hline 2 & $\begin{array}{l}\text { Menachem } \\
\text { Oberbaum et al.(22) }\end{array}$ & 2005 & $\begin{array}{l}\text { Journal of Alternative \& } \\
\text { Complementary Medicine }\end{array}$ & 2 & 2 & 2 & 0 & 0 & 6 \\
\hline 3 & $\begin{array}{l}\text { Bernadette } \\
\text { Glatthaar- } \\
\text { Saalmüller(23) }\end{array}$ & 2007 & $\begin{array}{l}\text { Canadian Journal Of } \\
\text { Physiology And } \\
\text { Pharmacology }\end{array}$ & 2 & 2 & 2 & 1 & 2 & 9 \\
\hline 4 & $\begin{array}{l}\text { Kerstin Roeska et } \\
\text { al.(24) }\end{array}$ & 2010 & $\begin{array}{l}\text { Journal of immune based } \\
\text { therapies and vaccines }\end{array}$ & 2 & 2 & 2 & 1 & 0 & 7 \\
\hline 5 & $\begin{array}{l}\text { Camila Monteiro } \\
\text { Siqueira et. al.(25) }\end{array}$ & 2013 & Homeopathy & 2 & 2 & 2 & 2 & 1 & 9 \\
\hline \multicolumn{10}{|c|}{ Clinical observational retrospective studies } \\
\hline 6 & $\begin{array}{l}\text { Ana Luiza Marques } \\
\text { de Oliveira et al.(26) }\end{array}$ & 2011 & $\begin{array}{l}\text { International Journal of } \\
\text { High Dilution Research }\end{array}$ & 2 & 2 & 2 & 2 & 0 & 8 \\
\hline 7 & $\begin{array}{l}\text { Robert T Mathie et } \\
\text { al.(27) }\end{array}$ & 2013 & Homeopathy & 2 & 2 & 2 & 2 & 1 & 9 \\
\hline \multicolumn{10}{|c|}{ Clinical trial } \\
\hline 8 & $\begin{array}{l}\text { Robert T Mathie et } \\
\text { al.(28) }\end{array}$ & 2015 & $\begin{array}{l}\text { Cochrane Database of } \\
\text { Systematic Reviews }\end{array}$ & 2 & 2 & 2 & 1 & 2 & 9 \\
\hline \multicolumn{9}{|c|}{ Mean } & 8.12 \\
\hline
\end{tabular}




\section{Review of recently completed or currently undergoing homoeopathic efforts to treat SARS-} CoV-2 infection

As evident from above discussions, a vast clinical experience does exist for the immuneboosting effect of Homoeopathic medicines and its role in the prevention of viral infection. The Genus Epidemicus has been used during various disease outbreaks for preventing the spread of diseases like Cholera, Chikungunya, Japanese Encephalitis, and Dengue Fever, etc. with good results (29-30). Given the clinical success in those severe infectious diseases, Homoeopathy as an adjuvant to the standard of care is also being evaluated for the management of COVID-19.

The Ministry of Ayurveda, Yoga \& Naturopathy, Unani, Siddha, and Homoeopathy (AYUSH), Govt. of India has suggested the use of Arsenicum album - 30 for its possible role in preventing COVID19 infection. Inspired by this advisory from AYUSH, GoI, the first ever homoeopathic study in India against COVID-19 was conducted by N Parikh et al. between January to February 2020 (31). They suggested and prescribed Arsenicum album 30 as a preventive remedy for COVID-19 to more than 1500 patients and continued for a 6-weeks follow-up and found that none of the patients or family members had reported COVID-19 related symptoms during the follow-up till 21st April 2020 nor the name of a single member was found in the published list of COVID-19 positive cases in the relevant area where otherwise more than 1500 COVID-19 positive cases have been reported (31). This study is expected to assist the identification of a better treatment approach and guide further research.

Another study in Agra, India by the Naiminath Homoeopathic Medical College, Hospital \& Research Centre, Agra conducted a trial on 44 COVID-19 patients in Agra has shown that a homoeopathic medicine Bryonia alba was more beneficial than Arsenicum album (32). Yet another interesting study conducted in Italy by Andreas Valeri has come up with very encouraging results. Patients who tested positive for COVID-19 as also residing in the affected area and had contact with a positive case and presenting with cough, fever and weakness or throat pain and or dyspnoea were included in the study (33). This study included 50 individuals and the prescribed medications were, in order of frequency: Bryonia alba; Arsenicum album; Phosphorus flavus; Atropa belladonna; Antimonium tartaricum; Eupatorium perfoliatum; Phosphoricum acidum; unspecified patient's basic remedy; Lycopodium clavatum; Sulphur; Hepar sulphur; Kalium phosphoricum; Gelsemium sempervirens; Mercurius solubilis, Chelidomum majus, Spigelia anthelmia, Solanum dulcamara, Psorinum, Spongia tosta, Ferrum phosphoricum, Ruta graveolens, Causticum hahnemanni, Thuya occidentalis, Streptococcinum, Ignatia amara. An overall recovery of patients at resolution of specific symptoms was commonly observed (33). Unfortunately, main drawback of this study is that best among these 17 remedies used to treat COVID-19 was not mentioned clearly and thus it is very hard to draw a clear conclusion before further studies. Another recent study, by a Chinese group lead by Ka Lun Aaron To and Yuen Ying Yvonne Fok, has reported that the homoeopathic symptoms observed in 18 confirmed/suspected epidemiologically related cases in cluster outbreaks of COVID-19 in Hong Kong in early 2020 focusing mainly on the homoeopathic symptoms (34). This study indicates that either Bryonia alba or Gelsemium sempervirens can be used to treat those 18 patients of COVID-19 (34).

While these preliminary attempts of homoeopathic treatments or managements of COVID-19 and its symptoms will boost several more studies in future, each of them should conduct their studies more elaborately and report in as detail as possible to increase reproducibility with enhanced applicability of homoeopathy against COVID-19. 


\section{Conclusion}

The application of homoeopathic treatment is remarkably increasing globally day by day for both infectious and non-infectious disorders facilitated by scientific evidences (35-36). Moreover, homoeopathic system of medicines offers the sufficient evidences to be used as preventive and as treatment modality in various dreadful epidemics such as typhoid, cholera, yellow fever, scarlet fever, meningitis etc. epidemic cases, there is anecdotal evidence that homoeopathy was successful during the Spanish flu epidemic of 1918 to 1919, in which at least 20 million people died worldwide. According to the historian Julian Winston, the death rates for patients treated with homoeopathy were 1 to $2 \%$ compared to a 30 to $60 \%$ mortality for those treated with conventional physicians (37). Similarly a study done by Nair et. al. (38) shows that Bryonia alba 30C as a genus epidemicus was better than placebo in decreasing the incidence of chikungunya in Kerala during the epidemic outbreak in August-September 2007. Recent efforts including the Italian descriptive study (33) have also shown that the rate of hospitalization in group of 50 patients treated with homoeopathically for COVID-19 is zero. The above-mentioned evidences urge further integration of homoeopathy in the healthcare system, which could not only be used as a Complementary and Alternative Medicine but also be implemented as a 'Bio-medicine' to combat infectious outbreaks including COVID-19. Current systematic review suggests that the development of new therapies, including homoeopathy, that can prevent and / or treat disease becomes increasingly necessary not only in control of the severity of the infectious disease but also of help in halting the disease to a certain geographical area rather than spreading worldwide. Present study and the recently completed or ongoing homeopathic treatment efforts of COVID-19 will surely boost a large number of homoeopathic practitioners to apply these approaches for the successful cure or prevention of COVID-19 in near future.

\section{Acknowledgments}

The authors express their intense gratitude to Dr. Bindu Sharma, Research Officer $(\mathrm{H})$, Scientist- 4, Central Council for Research in Homoeopathy (CCRH), Ministry of AYUSH, Govt. of India; Prof. (Dr.) Arun B. Jadhav, Principal and Prof. (Dr.) Anita S. Patil, Dean, Faculty of Homoeopathy, Bharati Vidyapeeth (Deemed to be University) - Homoeopathic Medical College and Hospital (PostGraduate Research Centre), Pune, India for their constant support and guidance to improve this article. The authors also acknowledge the anonymous reviewers of this manuscript for their constructive suggestions to improve the quality of the article. This study was supported by the Dey Health Care and Research Foundation (http://dhcrforg), West Bengal, India and the Homoeopathic Seva Niketan (http://homoeopathicsevaniketan.co.in/), New Delhi, India. The authors also express their gratitude to their parents for their support and divine blessings. SKD acknowledges the postdoctoral associateship offered by Prof. Eddy Arnold, Rutgers University, USA.

\section{Conflict of interests}

Authors declare no conflict of interest.

\section{References}

(1) Mayo Clinic. Coronavirus disease 2019 (COVID-19) - Symptoms and causes. Retrieved on 14 April 2020. Available from: https://www.mayoclinic.org/diseasesconditions/coronavirus/symptoms-causes/syc-20479963.

\section{OPEN ACCESS}


(2) Hui DS, I Azhar E, Madani TA, Ntoumi F, Kock R, Dar O, et al. (2020). The continuing 2019-nCoV epidemic threat of novel coronaviruses to global health- The latest 2019 novel coronavirus outbreak in Wuhan, China. International Journal of Infectious Diseases, 91: 264-66.

(3) World Health Organization (WHO). WHO Director-General's opening remarks at the media briefing on COVID-19. Retrieved on 11 March 2020. Retrieved 12 March 2020. Available from : https://www.who.int/dg/speeches/detail/who-director-general-sopening-remarks-at-the-media-briefing-on-covid-19-11-march-2020.

(4) Centers for Disease Control and Prevention (CDC), USA. Symptoms of Coronavirus. Retrieved on 10 February 2020. Available from: https://www.cdc.gov/coronavirus/2019-ncov/symptoms-testing/symptoms.html.

(5) World Health Organization. Q\&A on coronaviruses (COVID-19). Retrieved on 11 March 2020. Available from: https://www.who.int/news-room/q-a-detail/q-acoronaviruses.

(6) Hopkins C. Ear, Nose and Throat surgery body of United Kingdom. Loss of sense of smell as marker of COVID-19 infection. Retrieved on 28 March 2020.

(7) Velavan TP, Meyer CG. (2020). The COVID-19 epidemics. Tropical Medicine \& International Health. p 278-80.

(8) Dey JK, Dey SK (2020). SARS-CoV-2 Pandemic, COVID-19 Case Fatality Rates and Deaths per Million Population in India. Journal of Bioinformatics, Computational and Systems Biology. 2(1): 110.

(9) World Health Organization. Laboratory testing for 2019 novel coronavirus (2019$\mathrm{nCoV}$ ) in suspected human cases. Retrieved on 13 March 2020. Available from: https://www.who.int/publications-detail/laboratory-testing-for-2019-novelcoronavirus-in-suspected-human-cases-20200117.

(10) Centers for Disease Control and Prevention, USA. 2019 Novel Coronavirus (2019$\mathrm{nCoV}$ ) Situation Summary. Retrieved on 26 January 2020. Available from: https://www.cdc.gov/coronavirus/2019-ncov/cases-updates/summary.html?CDCAA refVal=https $\% 3 \mathrm{~A} \% 2 \mathrm{~F} \% 2 \mathrm{Fwww} . \mathrm{cdc}$. gov\%2Fcoronavirus $\% 2 \mathrm{~F} 2019 \mathrm{ncov} \% 2 \mathrm{Fsummary}$. html.

(11) Centers for Disease Control and Prevention, USA. Real-Time RT-PCR Panel for Detection 2019-nCoV. 29 January 2020. Retrieved on 30 January 2020. Available from: https://www.cdc.gov/coronavirus/2019-ncov/lab/index.html?CDC AA refVal https\%3A\%2F\%2Fwww.cdc.gov\%2Fcoronavirus\%2F2019-ncov\%2Flab\%2Frt-pcrdetection-instructions.html.

(12) Centers for Disease Control and Prevention, USA. Coronavirus Disease 2019 (COVID19): Prevention and Treatment. Retrieved on 10 February 2020. Available from: https://www.cdc.gov/coronavirus/2019-ncov/prevent-getting-sick/prevention.html 
?CDC_AA_refVal=https\%3A\%2F\%2Fwww.cdc.gov\%2Fcoronavirus\%2F2019-ncov\%2F prepare\%2Fprevention.html

(13) World Health Organization. Advice for Public. Retrieved on 10 February 2020. Available from: https://www.who.int/emergencies/diseases/novel-coronavirus2019/advice-for-public.

(14) NPR.org. My Hand-Washing Song: Readers Offer Lyrics for A 20-Second Scrub. Retrieved on 20 March 2020. Available from: https://www.npr.org/sections/goatsandsoda/2020/03/17/814221111/my-handwashing-song-readers-offer-lyrics-for-a-20-second-scrub.

(15) Maragakis LL. Johns Hopkins University. Coronavirus, Social Distancing and Self Quarantine. $\quad$ Retrieved on 18 March 2020. Available from: https://www.hopkinsmedicine.org/health/conditions-and-diseases/coronavirus/ coronavirus-social-distancing-and-self-quarantine.

(16) Parker-Pope, Tara, The New York Times. Deciding How Much Distance You Should Keep. Retrieved on 20 March 2020. Available from: https://www.nytimes.com/2020/03/19/well/live/coronavirus-quarantine-socialdistancing.html.

(17) Sanders JM, Monogue ML, Jodlowski TZ, Cutrell JB (2020). Pharmacologic Treatments for Coronavirus Disease 2019 (COVID-19): A Review. The Journal of the American Medical Association. doi:10.1001/jama.2020.6019.

(18) Dey SK, Saini M, Dhembla C, Bhatt S, Rajesh AS, Anand V, Das HK, and Kundu S (2020). Suramin, Penciclovir and Anidulafungin Bind Nsp12, Which Governs the RNAdependent-RNA Polymerase Activity of SARS-CoV-2, with Higher Interaction Energy Than Remdesivir, Indicating Potential in the Treatment of Covid-19 Infection. OSF Preprints. doi:10.31219/osf.io/urxwh.

(19) World Health Organization. Covid-19 dashboard. Retrieved on 14 June, 2020. Available from: https://covid19.who.int/.

(20) Klein SD, Würtenberger S, Wolf U, Baumgartner S, Tournier A (2018). Physicochemical investigations of homeopathic preparations: A systematic review and bibliometric analysis-Part 1. The Journal of Alternative and Complementary Medicine. 24(5):409-421.

(21) Glatthaar-Saalmüller B, Fallier- Becker P (2001). Antiviral action of Euphorbium compositum and its components. Complementary Medicine Research. 8(4):207-212.

(22) Oberbaum M, Glatthaar-Saalmüller B, Stolt P, Weiser M (2005). Antiviral Activity of Engystol ${ }^{\circledR}$ : An In Vitro Analysis. Journal of Alternative \& Complementary Medicine. 11(5):855-62.

(23) Glatthaar-Saalmüller B (2007). In vitro evaluation of the antiviral effects of the homeopathic preparation Gripp-Heel on selected respiratory viruses. Canadian journal of physiology and pharmacology. 85(11):1084-90. 
(24) Roeska K, Seilheimer B (2010). Antiviral activity of Engystol ${ }^{\circledR}$ and Gripp-Heel ${ }^{\circledR}$ : an invitro assessment. Journal of immune based therapies and vaccines. 8(1):6.

(25) Siqueira CM, Costa B, Amorim AM, Gonçalves M, da Veiga VF, Castelo-Branco M, Takyia C, Zancan P, Câmara FP, Couceiro JN, Holandino C (2013). H3N2 homeopathic influenza virus solution modifies cellular and biochemical aspects of MDCK and J774G8 cell lines. Homeopathy. 102(01):31-40.

(26) de Oliveira AL, Holandino C, Siqueira CM (2011). The biotherapics Influenzinum and Oscilococcinum in the treatment of influenza virus flu. International Journal of High Dilution Research. 10(35):94.

(27) Mathie RT, Baitson ES, Frye J, Nayak C, Manchanda RK, Fisher P (2013). Homeopathic treatment of patients with influenza-like illness during the 2009 A/H1N1 influenza pandemic in India. Homeopathy. 102(03):187-92.

(28) Mathie RT, Frye J, Fisher P (2015). Homeopathic Oscillococcinum for preventing and treating influenza and influenza-like illness. Cochrane Database of Systematic Reviews. Volume: 1 .

(29) Saxena SK, Manchanda RK. Handbook of recent trends in Homoeopathy for Infectious Diseases in India and abroad. 1st ed. India: Central Council for Research in Homoeopathy, New Delhi; 2016: 8.

(30) Goddard J. Homeopathy in Epidemics and Pandemics. Available from: http://www.thecma.org.uk/cma_images/Jayney's\%20Presentation.pdf.

(31) Parikh N, Parikh D. Role of homoeopathy in covid-19 management- a clinical experience. World Journal of Pharmaceutical Research. 2020 May ; 9 (5):2459-2466. (DOI: 10.20959/wjpr20205-17504).

(32) Homeopathy drug untested for efficacy against COVID-19 widely distributed in Mumbai. Retrieved on 12 June 2020. Available from https://www.thehindu.com/news/cities/mumbai/placebo-effect-untestedhomoeopathy-drug-being-distributed-widely/article31645532.ece

(33) Valeri, A. "Symptomatic COVID-19 Positive and Likely Patients Treated by Homeopathic Physicians-An Italian Descriptive Study. [Internet]. Researchgate; 2020 Apr." Tertrieved on May 30 2020. Available from: https://www.researchgate.net/publication/340631586.

(34) To, Ka Lun Aaron, and Yuen Ying Yvonne Fok. "Homeopathic Clinical Features of 18 Patients in COVID-19 Outbreaks in Hong Kong." Homeopathy (2020). DOI: 10.1055/s0040-1710545.

(35) Rahman S, Dey JK (2018). A case report of plantar psoriasis treated with homoeopathy. J Homœopathic Links. 2018; 31 (04): 248-253. 
(36) Mukherjee A, Aswani MA, Jadhav AB (2019). An in-vitro Study to Evaluate the AntiBacterial Activity of Rauvolfia serpentina against Escherichia coli. International Journal of Health Sciences and Research. 9(12):39-43.

(37) Jacobs J (2018). Homeopathic Prevention and Management of Epidemic Diseases. Homeopathy. 107(03): 157-160.

(38) Nair KR, Gopinadhan S, Kurup TN, Aggarwal A, Varanasi R, Nayak D, Padmanabhan M, Oberai P, Singh H (2014). Homoeopathic Genus Epidemicus 'Bryonia alba' as a prophylactic during an outbreak of Chikungunya in India: A cluster -randomised, double -blind, placebo- controlled trial. Indian Journal of Research in Homoeopathy. 8(03):16065.

Received: June 14, 2020. Accepted: July 31, 2020

(c) International Journal of High Dilution Research.

Not for commercial purposes. 